\title{
Aortik Arka Embolize Olan Atriyal Septal Defekt Okluder Cihazının Hibrit Çıkartılma İşlemi: Çiviyi Çiviyle Sökme
}

\section{Hybrid Extraction of Aortic Arcus Embolizated Atrial Septal Defect Occluder Device: One Nail Drives Out Another}

Emre Özdemir,

Sadık Volkan Emren,

Mustafa Ozan Gürsoy,

Cem Nazlı

Katip Çelebi Üniversitesi, Atatürk Eğitim ve Araştırma Hastanesi, Kardiyoloji Kliniği

Geliş Tarihi/Received: 11 Haziran 2018

Kabul Tarihi/Accepted: 31 Ekim 2018

Yazışma Adresi: Emre Özdemir

Katip Çelebi Üniversitesi, Atatürk Eğitim ve

Araştırma Hastanesi, Kardiyoloji Kliniği

e-posta: emreozdemir27@yahoo.com.tr

\section{ORCID}

Emre Özdemir

https://orcid.org/0000-0003-0034-3022

\begin{abstract}
Öz
Atriyal septal defekt(ASD) eriskinlerdeki defektlerin de \% 30-33'ünden sorumludur. Sekundum ASD tedavisinde transkateter tedavi, uygun defektler için birinci basamak tedavi olarak yer almaktadır. 36 yaşında sekundum ASD tanısı olan hastanın başarılı transkateter kapatma işlemi sonrası ilk 24 saat içinde aortik arka embolize olduğunu fark ettik. Embolize olan cihazların snare ve biyopsi kateteri ile alınması bilinmekle birlikte, farklı olarak femoral artere başka bir ASD okluder cihaz ile çekilmesi sonrası buradan cerrahi ile alınmasını içeren bir vaka sunduk. Farkı yöntemler kullanıp başarı şansını yükseltmek için embolize olan cihaz çıkartılmasında hibrit yaklaşım her zaman akılda olmalıdır.
\end{abstract}

Anahtar Kelimeler: Transkateter atriyal septal defekt kapatma, Amplatzer Septal Okluder, emboli, aortik arkus

\section{Abstract}

Atrial septal defect (ASD) is also responsible for $30-33 \%$ of adult defects. Transcatheter treatment is the first-line treatment for secundum ASD treatment, If defect is appropriate. A 36-year-old ASD patient that had a successful transcatheter closure. The occluder embolization became, within the first 24 hours after procedure, to the aortic arcus. It is known that the devices with embolism are taken by snare and biopsy catheter, but differently, this case involving surgical removal after retraction to femoral artery by another ASD occluder device. Hybrid approach should always be mindful when removing embolized device with high success rate, using different methods.

Keywords: Transcatheter atrial septal defect closure, Amplatzer Septal Occluder, embolism, aortic arch

\section{GíRiş}

Atriyal septal defekt (ASD), çocuklardaki tüm konjenital kalp hastalıklarının \% 7-10'undan ve konjenital kalp hastalıklarına sahip erişkinlerdeki defektlerin de \% 30-33'ünden sorumludur(1). Sekundum ASD tedavisinde, 1970 yılında perkütan ASD kapatmanın tanımlanmasına kadar, cerrahi yolla ASD kapatılması temel tedavi yöntemi olarak on yıllar boyunca yer almıştır(2). Sekundum ASD tedavisinde transkateter tedavinin, yıllar içinde kompleksite, rimler ve defekt büyüklüğü açısından, cihazlar geliştikçe endikasyonu artarak ilerlemiştir. Bununla birlikte embolizasyon gibi hayati olabilecek işlem komplikasyonlarını da içerir. Burada işlemden sonra, 24 saat içinde, aortik arka embolize olan cihazın çıkartma işlemi sunulacaktır.

\section{OLGU}

Çarpıntı ve dispne yakınması olan 36 yaşında erkek hastanın EKG'si sinüs ritmi olup sağ dal bloğu

Atıf yapmak için: Özdemir E, Emren SV, Gürsoy MO, Nazlı C. Aortik Arka Embolize Olan Atriyal Septal Defekt Okluder Cihazının Hibrit Çıkartılma İ̧̧lemi: Çiviyi Çiviyle Sökme. Selcuk Med J 2019;35(2): 133-136 mevcut idi. Fizik muayenede pulmoner odakta 2/6 sistolik üfürüm saptandı. Transtorasik ekokardiyografi (TTE)'de interatriyel septum (IAS)'da devamlılık kaybı görülmesi üzerine transösefagiyal ekokardiyografi (TEE) yapıldı. TEE'de $25 \mathrm{~mm}$ boyutunda sekundum ASD ile uyumlu defekt izlendi (Şekil 1A). Aortik rim $2 \mathrm{~mm}$, posterior rim $15 \mathrm{~mm}$, inferior rim $22 \mathrm{~mm}$, superior rim $17 \mathrm{~mm}$ olarak ölçüldü (Şekil 1B). Defektin transkateter olarak kapatılmasına karar verildi. Hastaya genel anestezi altında yapılan perkütan ASD kapatma işleminde skopi altında ve üç boyutlu TEE de en geniş yerinde $26 \mathrm{~mm}$ olarak ölçülen İAS'deki defekt (Şekil 1C,) $28 \mathrm{~mm}$ likAmplatzer ${ }^{\mathrm{TM}}$ septal okluder cihazı (Abbott Medical, USA) ile genel anestezi eşliğinde başarılı olarak kapatıldı (Şekil 1D). İşlemden 24 saat sonra yapılan TTE'da İAS'de okluder cihazın olmadığı ve cihazın aortik arka embolize olduğu (Şekil 1E-F) gözlenmesi üzerine perkütan yolla çıkartılmak üzere kateter laboratuvarına alındı. Genel anestezi altında skopi ve TEE eşliğinde sol femoral arter ponksiyonu 

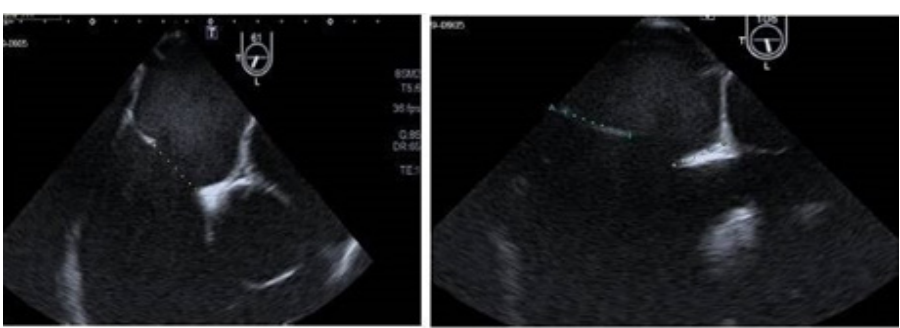

Resim 1A
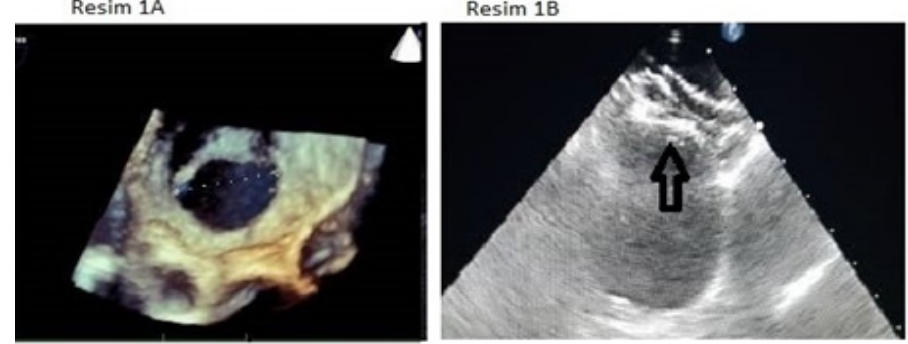

Resim $1 \mathrm{C}$

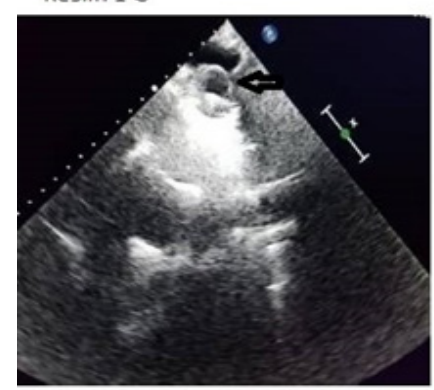

Resim 1E

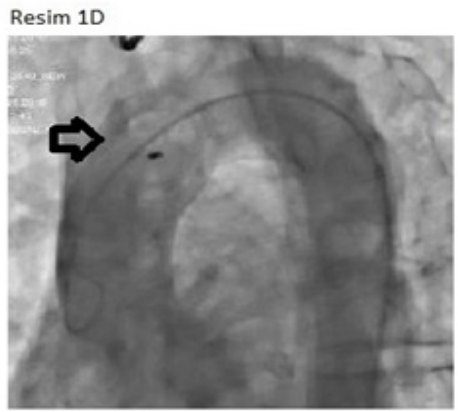

Resim 1 F

Şekil 1. Şekil 1A: TEE'de $25 \mathrm{~mm}$ olan sekundum ASD izlenmekte, Şekil 1B: Rimler yeterli izlenmektedir. Şekil 1C: Üç boyutlu TEE'de $26 \mathrm{~mm}$ olarak ASD ölçülmüştür. Şekil 1D: Siyah okla belirtilen ASD cihazının uygun yerleşimi görülmektedir. Şekil $1 \mathrm{E}$ ve F: Siyah okla belirtilen cihaz işlemden 24 saat sonra TTE'de ve anjiyografide arkus aortada yer almaktadır.

sonrası snare ile cihaz kavranmaya çalışıldı ancak başarılı (Şekil 2A) olunamadı. Biopsi kateteri ile cihaz tutulmaya çalışıldı ancak cihaz kavranmasına rağmen çekilemedi (Şekil 2B). Takibinde femoral arterden ASD okluder delivery sistemi ile embolize olan cihazın distaline ilerlenerek 24 mm 'lik ikinci bir Amplatzer TM septal okluder cihazı (Abbott Medical, USA) açılarak embolize olan cihaz, femoral artere çekildi (Şekil 2C-D-E-F). Cihaz sol süperfisiyal femoral artere (SFA) kadar çekilebildi (Şekil 2G). Sağ femoral aterden ponksiyon ile sol SFA' ya snare ile ilerlenmesi sonrası cihaz snare ve biopsi kateteri (Şekil $2 \mathrm{H}$ ) tutulmaya çalışıldı ancak başarılı olunamayınca cerrahi olarak cihaz çıkartıldı ve ASD cerrahi yol ile kapatıldı.
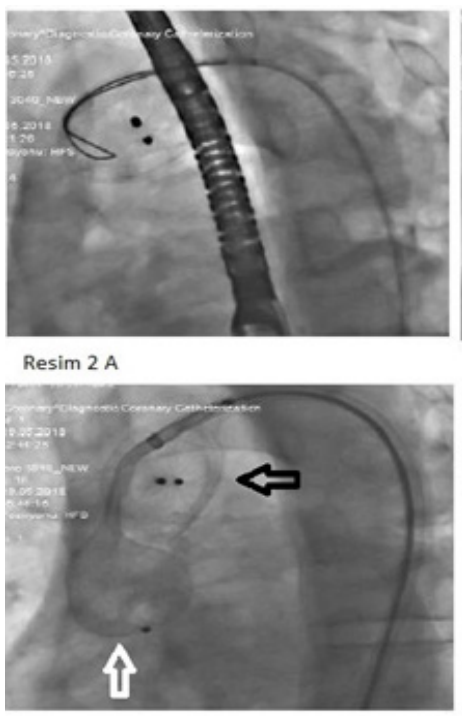

Resim 2 C

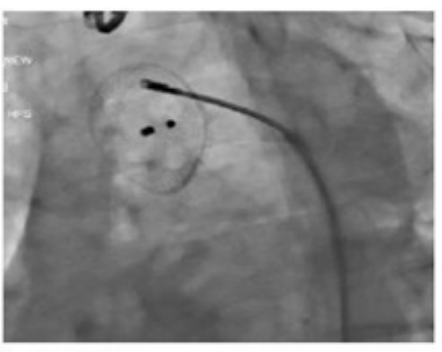

Resim 2 B

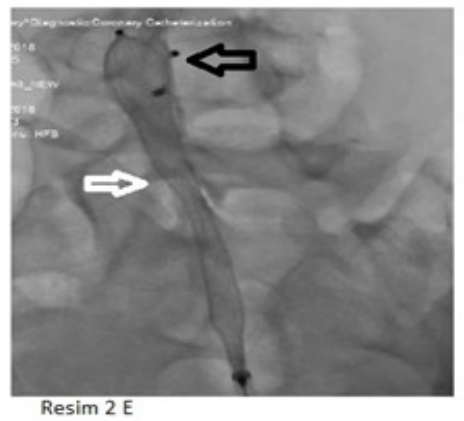

Resim 2 D

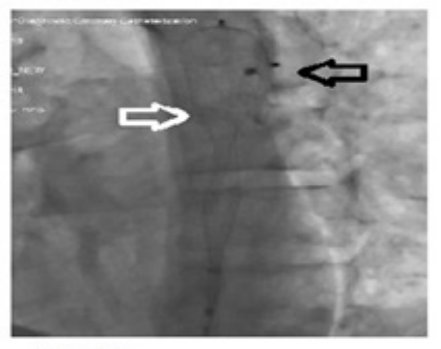

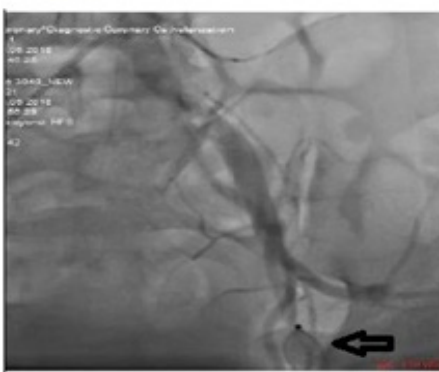

Resim 2 G
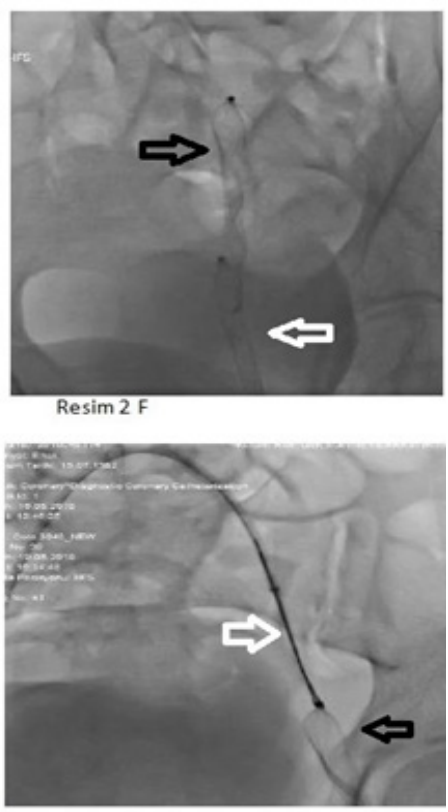

Resim $2 \mathrm{H}$

Şekil 2. Cihaz arkus aortada snare (Şekil 2A) ve biopsi kateteri (Şekil 2B) tutulmaya çalışıldı ancak başarılamadı. Siyah okla gösterilen embolize cihazın distalinde beyaz okla gösterilen başka bir Amplatzer ${ }^{\mathrm{TM}}$ septal okluder cihazı açılarak femoral artere kadar çekildi (Şekil 2-C-D-E-F-G). Takibinde burda sıkışan cihaz gene snare ve biopsi kateteri (Şekil $2 \mathrm{H}$ ) ile perkütan olarak alınamayınca, cerrahi olarak çıkartıldı

\section{TARTIŞMA}

Perkütan ASD kapatmanın 1970'lerdeki tanımından sonra gelişen teknik ve cihaz ile sekundum ASD için kabul gören ve birinci basamak haline gelen tedavi şekli olmuştur. Perkütan ASD kapatmanın güvenliği bir 
yana, beklenmeyen komplikasyonlar ile de birliktedir. $\mathrm{Bu}$ komplikasyonlar içinde IAS yaralanması, aortik erozyon sonrası perikardiyel tamponad, trombüs oluşumu ve embolizasyon yer almaktadır (3). Cihaz embolizasyonu \%0,3-0,6 ile nadir bir komplikasyon olsa da (4) cerrahi gereksinim doğuran en sık komplikasyondur ve hayati riskler barındırır. $\mathrm{Bu}$ oranın bir derlemede \%1,4'e kadar çıkabildiği saptanmıştır (5). Patent fotamen ovale (PFO) kapatma ile kıyaslığında ASD kapatmada cihaz boyut seçimi, rimlerin yeterli uzunlukta olmasına rağmen cihazı taşıma için yetersiz güçte (floppy) olması gibi nedenlerden embolizasyon daha sık görülmektedir. İşlemden sonra 2. yıl gibi, geç embolizasyonlar da (6) bildirilse de çoğunlukla ilk 12-24 saat içinde embolizasyon gerçekleşir. Embolizasyonda küçük cihaz boyutu, rimlerin yetersiz yada floppy yapıda olması, operatörün deneyim eksikliği nedenli cihazın tam oturtulamaması yada aşırı çekilmesi gibi etmenler rol oynamaktadır. Rimlerin yeterliliği ve maksimum defekt boyutu için balon sizing ve TEE ölçümü için çeşitli farklı öneriler vardır. Bazı yayınlarda balon ölçümün TEE varken gerekmediğini belirtirken (7), bazı yayınlarda (8) ise balon ile yapılan ölçümün maksimal en geniş ölçüm olduğundan TEE'den daha değerli olduğunu söylemektedir.

Embolizasyonlar en sık pulmoner trunkus'a olsa da bizim vakamızdaki gibi aortik arka da embolizasyonlar söz konudur. Bir çok cihaz perkütan olarak alınabilmektedir ancak büyük cihazlar yada hasta anatomisinin uygun olmaması nedenli cerrahi teknik, çevre dokuların yaralanmaması adına faydalı olabilmektedir (9). Embolize olan cihazlar boyut ve anatomi bağımlı olarak \%70 oranında geri alınabilmektedir (10) Geri almada sağ atrial disk üstündeki vida noktasının yakalanması ile sheate geri alınma gibi prosedurler tanımlansa da cihazın pozisyonuna bağlı bu işlemin başarısı zor olmaktadır (10). Cihazın biopsi kateterleri yada Amplatz GooseNeck® Snare( Abbott Medical, USA) ile geri alınması söz konusu olsa da başarısız olunmasında cerrahi güvenli bir seçenektir. Hatta, Her et al (11). da venöz sisteme embolize olan cihazın farklı bir teknik olarak cihazın bel kısmında yakalanarak çıkarılmasını sunmuşlardır.

Bizim vakamızda, merkeziminiz deneyimli bir merkez olması ile birlikte, üç boyutlu ekokardiyografi sonrası 26 mm ölçülen defektin (Şekil 1A-B-C) uygun $28 \mathrm{~mm}$ lik Amplatzer ${ }^{\mathrm{TM}}$ septal okluder cihazı (Abbott Medical, USA) ile başarılı okluzyonu, işlem sonrası Minnesota manevrasına rağmen cihazın stabil olması ile birlikte (Şekil 1D), cihaz 24. saat içinde embolize olmuştur. Snare ve biopsikateteriile başarısızolunması sonrası ikinci bir $24 \mathrm{~mm}$ Amplatzer ${ }^{\mathrm{TM}}$ septal okluder cihazı (Abbott Medical, USA) embolize olan cihazın distalinde yerleştirme sistemi ile ilerletilerek açılmış ve distale kadar çekilebilmiş (Şekil 2C-D-E-F). Cihaz sol süperfisiyal femoral artere (SFA) kadar çekilebilen cihazın arter ponksiyon alanından çıkartılamaması nedenli sağ femoral aterden ponksiyon ile sol SFA' ya snare ile ilerlenerek cihaz tekrar tutulmaya çalışılmış ancak sıkıştığı için alınamamıştır (Şekil 2G-H). Bunun sonucunda femoral arterden cerrahi yolla cihaz çıkartılıp, hasta gene cerrahi yol ile ayni seansta kalp damar cerrahisi tarafından torakotomi ile ASD kapatılma işlemi yapılmıştır.

Sonuç olarak; Perkütan ASD kapatma uygun anatomili sekundum ASD'lerde altın standart olsa da embolizasyon hayati olabilecek korkulan ama nadir bir komplikasyondur. Embolilerin çoğu ilk 24 saate olmakta ve gene çoğu pulmoner yatağa embolize olduğundan başarılı olarak perkütan alınabilmektedir. Snare ve biopsi kateteri ile alınana vakalar bilinmekle birlikte biz ikinci bir ASD okluderler cihazın çekilebileceğini gösterdik. Bir nevi 'çivi çivi söker' prensibi de olsa farklı yöntemlerin kullanılabileceği kesindir. Hibrit yaklaşım akılda olmakla beraber, başarılı olunamayan vakalarda çevre dokuların zedelenmemesi adına cerrahi seçenek masada olmalıdır.

Çıkar Çatışması: Çalışmada herhangi bir çıkar çatışması yoktur.

Finansal Çıkar Çatışması: Çalışmada herhangi bir finansal çıkar çatışması yoktur.

Yazışma Adresi: Emre Özdemir,

Katip Çelebi Üniversitesi, Atatürk Eğitim ve Araştırma Hastanesi, Kardiyoloji Kliniği, Izmir Türkiye

e-posta: emreozdemir27@yahoo.com.tr

Telefon: +905065198208

\section{KAYNAKLAR}

1. Hoffman JI, Kaplan S. The incidence of congenital heart disease.J Am Coll Cardiol 2002;39:1890-900.

2. King $\mathrm{T}$, Thompson S, Steiner $\mathrm{C}$, et al. Secundum atrial septal defect. Nonoperative closure during cardiac catheterization. JAMA 1976;235:2506-9.

3. Moore J, Hegde S, El-Said H, et al. Transcatheter device closure of atrial septal defects: A safety review. JACC Cardiovasc Interv 2013;6:433-42.

4. Son JW, Park JS. Subacute, silent embolization of amplatzer atrial septal defect closure device to the pulmonary artery. J Cardiovasc Ultrasound 2012;20:201-4.

5. Amanullah MM, Siddiqui MT, Khan MZ, et al. Surgical rescue of embolized amplatzer devices. J Card Surg 2011;26:254-8. 
6. Lysitsas DN, Wrigley B, Banerjee P, et al. Presentation of an embolised Amplatzer septal occluder to the main pulmonary artery 2 years after implantation. Int J Cardiol 2009;131:1067.

7. Amin Z, Daufors DA. Balloon sizing is not necessary for closure of secundum atrial septal defects. J Am Coll Cardiol 2005;45(Suppl 1):317.

8. Helgason H, Johansson M, Söderberg B, et al. Sizing of atrial septal defects in adults. Cardiology 2005;104:1-5.

9. Costache V, Chavanon O, Thony F, et al. Aortic arch embolization of an amplatzer occluder after an atrial septal defect closure: Hybrid operative approach without circulatory arrest. Eur J Cardiothorac Surg 2005;28:340-2.
10. Levi DS, Moore JW. Embolization and retrieval of the Amplatzer septal occluder. Catheter Cardiovasc Interv 2004;61:543-7.

11. Her AY, Lim KH, Shin ES. Transcatheter retrieval of embolized atrial septal defect occluder device by waist capture technique. Int Heart J. 2018;59(1):226-8. 